\section{Preview: XXII International Materials Research Congress 2013}

\author{
August 11-15, 2013 Cancun, Mexico \\ www.mrs-mexico.org.mx/imrc2013 www.mrs.org/imrc2013/
}

$\mathbf{T}$ he XXII International Materials Research Congress (IMRC) 2013, to be held on August 11-15, 2013, in Cancun, Mexico, is a joint meeting of the Sociedad Mexicana de Materiales (SMM) and the Materials Research Society (MRS). The Meeting Chairs are Claudia Gutiérrez Wing of Instituto Nacional de Investigaciones Nucleares, Mexico; David Lederman of West Virginia University, USA; Xavier Mathew of Universidad Nacional Autonoma de Mexico, Mexico; and Fiona Meldrum of the University of
Leeds, UK; and the chair of the Congress is Sergio Mejia Rosales of Autonomous University of Nuevo León, Mexico.

The Congress will feature 30 symposia covering nanoscience and nanotechnology, biomaterials, materials for energy, fundamental materials science, materials characterization, materials for environmental applications, and magnetic and electronic materials as well as topics on archaeological issues in materials science and on academy-industry relationships. Oral and poster presentations will be given as well as tutorials, and there will be an equipment exhibition.

Among the plenary speakers are Walter de Heer (Georgia Institute of Technology), presenting a lecture on nanostructured graphene; Ron Naaman (Weizmann Institute of Science, Israel), presenting a lecture on spintronics; Eric Fullerton (University of California-San Diego), on magMRS netic storage and memory applications; Isaac Hernández-Calderón (Cinvestav, Mexico), on semiconductors; and Shigeo Ted Oyama (University of Tokyo), on the preparation of a hydrogen-selective inorganic membrane.

For additional information on the Congress, access www.mrs-mexico.org.mx/ imrc2013.

\title{
Preview: MRS sponsors joint symposia with JSAP
}

\author{
September 16-20, $2013 \quad$ Kyoto, Japan \\ www.jsap.or.jp www.mrs.org/joint-meetings
}

$\mathbf{T}$ he Materials Research Society and the Japan Society of Applied Physics are jointly sponsoring 23 symposia as part of the 74th Japan Society of Applied Physics Autumn Meeting, which will be held September 16-20, 2013, at
Doshisha University in Kyoto, Japan. This is the second recent collaborative effort between the two societies.

Symposia topics include nanocarbon devices and materials, ferroelectric and multiferroic materials by nano- structure engineering, smart materials, rare-earth-doped materials for photonic applications, nanodiamond-from basics to medical and other potential applications, and photovoltaics materials and devices for terrestrial and space applications. Akira Fujishima, President of Tokyo University of Science, will present the Kavli Lecture on photocatalysis.

More information can be accessed at www.mrs.org/joint-meetings.
MRS ENERGY OS SUSTAINABILITY A Review Journal

EDITORS-IN-CHIEF David S. Ginley, National Renewable Energy Laboratory David Cahen, Weizmann Institute of Science Sally M. Benson, Stanford University
Coming Early 2014

MRS Energy \& Sustainability: A Review Journal will publish reviews on key topics in materials research and development as they relate to energy and sustainability. Topics to be reviewed include new R\&D of both established and new areas; interdisciplinary systems integration; and objective application of economic, sociological, and governmental models, enabling research and technological developments. The reviews will be set in an integrated context of scientific, technological and sociological complexities relating to environment and sustainability. The intended readership is a broad spectrum of scientists, academics, policy makers and industry professionals, all interested in the interdisciplinary nature of the science, technology and policy aspects interdisciplinary nature of the
of energy and sustainability.

For more information, including author benefits, open access options, indexing and proposal form, visit www.mrs.org/energy-sustainability-journal.

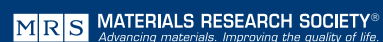

